\title{
Effectiveness of a Video-assisted Demonstration Program on Knowledge and Practice regarding Maintenance of Asepsis in Labor Room among Final Year Auxiliary Nursing Midwifery Students
}

\author{
${ }^{1}$ Suvarna S Pinnapati, ${ }^{2}$ Sudha Raddi
}

\begin{abstract}
Pregnancy and childbirth are the important events of a women's life. The place of delivery plays an important role in child survival and safe motherhood. The child born in unhygienic condition is more to get infection. A properly assisted delivery with skilled personnel and following aseptic precaution is highly advantageous to both mother and fetus during delivery. The objectives of the study were to assess the knowledge and practices regarding maintenance of asepsis in labor room among ANM students as measured by structured questionnaire and observation checklist, to evaluate effectiveness of a video-assisted demonstration on knowledge and practice regarding maintenance of asepsis in labor room among auxiliary nursing midwifery (ANM) students, to find out an association between pretest knowledge and practice scores with selected demographic variables.

The study was conducted using randomized control trial. Demographic variables analyzed for the study were age, religion, monthly family income and residence. The study was conducted on sample of 60 selected final year ANM students of KLEU's Institute of Nursing Sciences, Belgaum, and BIMS ANM Training Centre, Belgaum, using simple random sampling technique. Data collection were through structured knowledge questionnaire and observation checklist. Data obtained were tabulated and analyzed in terms of objectives of the study using descriptive and inferential statistics. The study findings showed that there is increase in post-test knowledge and practice regarding maintenance of asepsis in labor room after administration of video demonstration program compare to pretest.
\end{abstract}

Keywords: Effectiveness, Final year ANM students, Maintenance of asepsis, Video-assisted demonstration program.

How to cite this article: Pinnapati SS, Raddi S. Effectiveness of a Video-assisted Demonstration Program on Knowledge and Practice regarding Maintenance of Asepsis in Labor Room among Final Year Auxiliary Nursing Midwifery Students . J South Asian Feder Obst Gynae 2015;7(3):109-112.

\footnotetext{
${ }^{1}$ Vice Principal, ${ }^{2}$ Principal

${ }^{1}$ Department of Obstetrics and Gynecology, AV School of Nursing, Bengaluru, Karnataka, India

${ }^{2}$ Department of Obstetrics and Gynecology, KLE Institute of Nursing Sciences, Belgaum, Karnataka, India
}

Corresponding Author: Suvarna S Pinnapati, Vice Principal Department of Obstetrics and Gynecology, AV School of Nursing, Bengaluru, Karnataka, India, Phone: 9845732545 e-mail: suvarna965@gmail.com
Source of support: Nil

Conflict of interest: None

Date of received: 8 June 2015

Date of acceptance: 12 September 2015

Date of publication: December 2015

\section{INTRODUCTION}

Pregnancy and delivery is a normal physiological process. Most of the time, the women achieve normal pregnancy outcome without any complication. ${ }^{1}$ Maternal health is a critical topic in global development. Maternal ill health and death impacts families, communities and societies and has far reaching effects across socioeconomic strata. ${ }^{3}$ But, too many mothers and children in the world are dying and suffering from the effects ill health, poor nutrition and unhygienic condition. ${ }^{1}$

Asepsis is the absence of pathogens and is an effort to keep a client as free from contamination from microorganisms as possible. Aseptic technique is employed in labor room to maximize and maintain asepsis. The goals of aseptic technique are to protect the patient from infection and to prevent the spread of pathogens. Often, practices that clean (remove dirt and other impurities), sanitize (reduce the number of microorganisms to safe levels) or disinfect (remove most microorganisms but not highly resistant ones) are not sufficient to prevent infection. Aseptic technique is vital in reducing the maternal and infant morbidity and mortality associated with infections. ${ }^{4}$ The delivery ${ }^{2}$ room, like the must be aseptically clean for the protection of both the mother and the child-the mother from microorganism against which he has no defense as yet. ${ }^{5}$

The healthcare professional in general and nurses in particular play a vital role to ensure that the newborn has best possible beginning of life and the nurse must be aware of the potential problems and be alert to the newborns changing condition and to intervene appropriately when necessary. The nurse is the first healthcare provider who has direct contact with the neonate during birth. ${ }^{6}$ 


\section{METHODOLOGY}

An evaluative research approach was used in the study. The research design used for the study was randomized control trial. The main focus of the study was to evaluate the effectiveness of a video-assisted demonstration program on knowledge and practice regarding maintenance of asepsis in labor room among final year auxiliary nursing midwifery (ANM) students. The research variables were knowledge and practice regarding maintenance of asepsis in labor room. The samples were final year ANM students of selected ANMTc, Belgaum, Karnataka.

The sample size of the present study was 60 selected final year ANM students. The samples for the present study were selected by a simple random sampling technique. The data collection instruments were structured knowledge questionnaire and observation checklist.

The maximum scores for knowledge were 36 . The knowledge was divided into three categories viz adequate, moderate, inadequate according to mean percentage. The observation checklist was used to assess the practice towards maintenance of asepsis in labor room. The maximum score for the practice was 13 . The practice scores were divided into three categories viz adequate, moderate, inadequate according to mean percentage.

The reliability of the tool was tested by split half method by using Karl Pearson's coefficient of correlation formula. The reliability result is $r=0.99$. The collected data were analyzed by using descriptive and inferential statistics.

\section{RESULTS}

Data analysis (Tables 1 to 4) for level of knowledge in experimental group revealed that in pretest majority of final year ANM students 16 (53.33\%) had moderate knowledge and $14(46.66 \%)$ had inadequate knowledge and post-test majority of final year ANM students 23 (76.66\%) had

Table 1: Comparison of pre- and post-test scores of knowledge in experiment and control group by paired t-test $(n=60)$

\begin{tabular}{|c|c|c|c|c|c|c|c|}
\hline Groups & & Mean & $S D$ & Mean diff. & $S D$ diff. & Paired t-test & $p$-value \\
\hline \multirow[t]{2}{*}{ Experiment } & Pretest & 49.00 & 9.60 & & & & \\
\hline & Post-test & 64.22 & 10.54 & -15.22 & 12.25 & -6.8087 & $0.0000^{*}$ \\
\hline \multirow[t]{2}{*}{ Control } & Pretest & 42.33 & 8.63 & & & & \\
\hline & Post-test & 48.33 & 7.15 & -6.00 & 12.21 & -2.6926 & $0.0117^{*}$ \\
\hline
\end{tabular}

${ }^{*} p<0.05$

Table 2: Comparison of pre- and post-test scores of practice in experiment and control group by paired t-test $(\mathrm{n}=60)$

\begin{tabular}{|c|c|c|c|c|c|c|c|}
\hline Groups & & Mean & $S D$ & Mean diff. & SD diff. & Paired t-test & $p$-value \\
\hline \multirow[t]{2}{*}{ Experiment } & Pretest & 47.11 & 10.27 & & & & \\
\hline & Post-test & 57.89 & 8.42 & -10.78 & 11.90 & -4.9619 & $0.0000^{*}$ \\
\hline \multirow[t]{2}{*}{ Control } & Pretest & 55.33 & 12.94 & & & & \\
\hline & Post-test & 57.56 & 11.14 & -2.22 & 4.82 & -2.5246 & $0.0173^{*}$ \\
\hline
\end{tabular}

${ }^{*} p<0.05$

Table 3: Comparison of experiment and control groups with respect to pre- and post-test and their gain knowledge scores $(\%)$ by unpaired t-test $(n=60)$

\begin{tabular}{|c|c|c|c|c|c|c|}
\hline Variables & Groups & $n$ & Mean & $S D$ & $t$-value & $p$-value \\
\hline \multirow[t]{2}{*}{ Pretest } & Experiment & 30 & 49.00 & 9.60 & 2.8297 & $0.0064^{*}$ \\
\hline & Control & 30 & 42.33 & 8.63 & & \\
\hline \multirow[t]{2}{*}{ Post-test } & Experiment & 30 & 64.22 & 10.54 & 6.8331 & $0.0000^{*}$ \\
\hline & Control & 30 & 48.33 & 7.15 & & \\
\hline \multirow[t]{2}{*}{ Gain } & Experiment & 30 & 15.22 & 12.25 & 2.9216 & $0.0050^{*}$ \\
\hline & Control & 30 & 6.00 & 12.21 & & \\
\hline
\end{tabular}

${ }^{*} p<0.05$

Table 4: Comparison of experiment and control groups with respect to pre- and post-test and their gain practice scores $(\%)$ by unpaired t-test $(n=60)$

\begin{tabular}{|c|c|c|c|c|c|c|}
\hline Variables & Groups & $n$ & Mean & $S D$ & $t$-value & $p$-value \\
\hline \multirow[t]{2}{*}{ Pretest } & Experiment & 30 & 47.11 & 10.27 & -2.7252 & $0.0085^{*}$ \\
\hline & Control & 30 & 55.33 & 12.94 & & \\
\hline \multirow[t]{2}{*}{ Post-test } & Experiment & 30 & 57.89 & 8.42 & 0.1308 & 0.8964 \\
\hline & Control & 30 & 57.56 & 11.14 & & \\
\hline \multirow[t]{2}{*}{ Gain } & Experiment & 30 & 10.78 & 11.90 & 3.6504 & $0.0006^{*}$ \\
\hline & Control & 30 & 2.22 & 4.82 & & \\
\hline
\end{tabular}

${ }^{*} p<0.05$ 
moderate knowledge, five (16.66\%) had adequate knowledge and two (6.66\%) had inadequate knowledge.

Data analysis for level of knowledge in control group revealed that in pretest majority of final year ANM students $24(80 \%)$ had inadequate knowledge and six (20\%) had moderate knowledge. In post-test majority of final year ANM students, 16 (53.33\%) had inadequate knowledge and 14 (46.66\%) had moderate knowledge.

Whereas the data analysis for level of practice in experimental group revealed that in pretest majority of final year ANM students, 19 (63.33\%) had inadequate practice and $11(36.66 \%)$ had moderate practice. In posttest majority of final year ANM students 26 (86.66\%) had moderate practice, three $(10 \%)$ had inadequate practice and one (3.33\%) had adequate practice (Graphs 1 and 2).

Data analysis for level of practice in control group revealed that, in pretest majority of final year ANM students, 19 (63.33\%) had moderate practice, nine (30\%) had inadequate practice and two (6.66\%) had adequate practice. In post-test majority of final year ANM students,

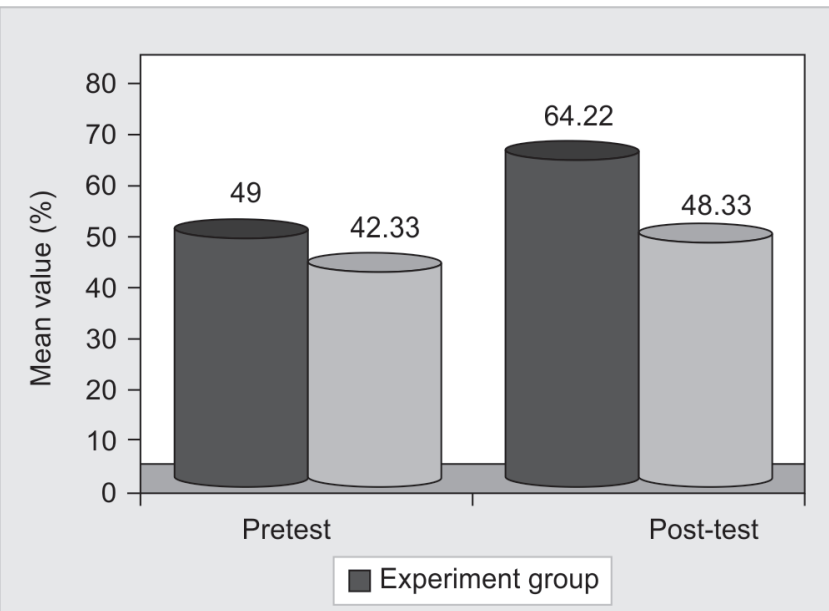

Graph 1: Experiment group depicts pretest and post-test results of the experiment group in the research

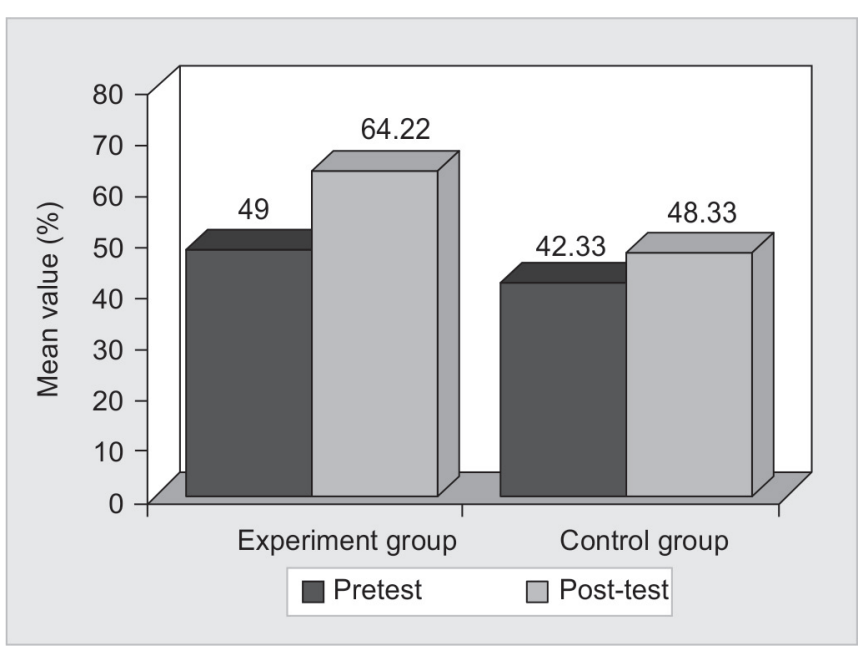

Graph 2: Experiment and control group pretest and post-test results in the research
$23(76.66 \%)$ had moderate practice, six (20\%) had inadequate practice and one (3.33\%) had adequate practice.

Data analysis for effectiveness of video demonstration program reveals that the mean knowledge difference of post-test and pretest score in experimental group (15.22) is higher than the mean difference of post-test and pretest score in control group (6.00). mean practice difference of post-test and pretest score in experimental group (10.78) is higher than the mean difference of post-test and pretest score in control group (2.22).

The variables age found to have significant association between post-test knowledge scores in experimental group and control group at 0.05 level of significance, family income found to have significant association between post-test knowledge scores in control group at 0.05 level of significance, residence found to have significant association between post-test knowledge scores in experimental group at 0.05 level of significance.

\section{DISCUSSION}

\section{Findings related to Knowledge of Final Year ANM Students about Maintenance of Asepsis in Labor Room in Experimental and Control Groups}

In experimental group, findings reveal that pretest majority of final year ANM students 16 (53.33\%) had moderate knowledge and $14(46.66 \%)$ had inadequate knowledge. In post-test majority of final year ANM students, $23(76.66 \%)$ had moderate knowledge, five $(16.66 \%)$ had adequate knowledge and two (6.66\%) had inadequate knowledge. In control group, findings reveal that pretest majority of final year ANM students $24(80 \%)$ had inadequate knowledge and six (20\%) had moderate knowledge. In post-test majority of final year ANM students, 16 (53.33\%) had inadequate knowledge and 14 (46.66\%) had moderate knowledge. Similar findings were seen in a study conducted by Renuka PR. ${ }^{7}$ The results showed that the mean pretest knowledge scores of samples about infection control strategies in over area before administering self instructional module was 9.23 whereas post-test knowledge after administering self instructional module was 22.38 .

\section{Findings related to Practice of Final Year ANM Students about Maintenance of Asepsis in Labor Room in Experimental and Control Groups}

In experimental group, findings reveal that pretest majority of final year ANM students 19 (63.33\%) had inadequate practice and $11(36.66 \%)$ had moderate practice. In post-test majority of final year ANM students, $26(86.66 \%)$ had moderate practice, three $(10 \%)$ had inadequate practice and one (3.33\%) had adequate 
practice. In control group findings reveals that pretest majority of final year ANM students 19 (63.33\%) had moderate practice, nine $(30 \%)$ had inadequate practice and $2(6.66 \%)$ had adequate practice. In post-test majority of final year ANM students 23 (76.66\%) had moderate practice, six (20\%) had inadequate practice and one (3.33\%) had adequate practice. Similar findings were seen in a study conducted by Renuka PR. ${ }^{7}$ The results showed that the mean pretest practice scores of samples about infection control strategies in over area before administering selfinstructional module was 13.55 whereas post-test practice after administering self-instructional module was 36.36 .

\section{CONCLUSION}

The findings of the study showed that the actual gain score in experimental group was consistently high in all the areas included in the study compared to control group. The paired $\mathrm{t}$-test computed between mean posttest knowledge and practice scores with mean pretest knowledge score and practice score in experimental group indicated significant gain in knowledge and increased practice skills in all areas compared to control group and unpaired $\mathrm{t}$-test between post-test knowledge and practice scores in experimental group and post-test knowledge and practice in control group showed that there is gain in knowledge and practice in experimental group compared to control group. Thus, it is concluded that the video demonstration program on maintenance of asepsis in labor room is effective.

\section{REFERENCES}

1. Wong and Perry. Maternal and child nursing care library of congredd. Cataloging in publication data: 2006.

2. Child survival safe motherhood. Care at the time of delivery. Ministry of Health and family welfare; 1992. p. 29-110.

3. Pulitzer. (Documents on internet); 2010 March 19.

4. Manngram, Alicia, Horan T, Pearson M, Silver LC, Jarvis W. (Document on internet); 2011.

5. Doodsdpogi. Documents on internet; 2011 Nov 21st.

6. Padmanabam P, Raman PS. Innovation and challenges in reducing maternal mortality health population. Nutr 2010 Jun;27(2):202-209.

7. Renuka PR. A study to assess the effectiveness of self instructional module on knowledge and practice of infection control strategies followed by staff nurses working in labor rooms at selected Medical College Attached Hospital of Gujarat State. 